\title{
Feasibility of R1270 as an Alternative Refrigerant to Replace R134a in Refrigerator
}

\author{
Kamin Sumardi*, Devinda Naufal, Muhammad Farhan Maulana, Ega Taqwali Berman \\ Departemen of Mechanical Engineering Education \\ Universitas Pendidikan Indonesia \\ Bandung, Indonesia \\ *kaminsumardi@upi.edu, devindanaufa105@student.upi.edu, mufarhan@student.upi,edu, egatb@upi.edu
}

\begin{abstract}
This study aims to determine the feasibility of $\mathrm{R} 1270$ as an alternative refrigerant to replace $\mathrm{R} 134 \mathrm{a}$ in the refrigerator. The test is carried out on a showcase refrigerator with a volume capacity of 210 liters. The research method used experiment with drop in substituted refrigerant technique. In the initial stage, the performance measurement of the refrigerator using R134a is carried out as the base line. After that, the refrigerant is replaced by $\mathrm{R} 1270$ by charging the weight of the refrigerant as much as $30 \%$ of the base line. The test data was collected for 60 minutes by recording the parameters of pressure, temperature, electric current and cooling time every six minutes. In the final stage, data processing and analysis are carried out to determine the feasibility of using $\mathrm{R} 1270$ as refrigerant in refrigerators. The results showed that COP increased $26 \%$ and the evaporator temperature was $6 \mathrm{C}$ lower after replacing R134a by $\mathrm{R1270}$. These results have implications for the feasibility of $\mathrm{R} 1270$ to replace $\mathrm{R} 134 \mathrm{a}$ as the refrigerator working fluid.
\end{abstract}

\section{Keywords—performance, refrigerator, refrigerant, showcase}

\section{INTRODUCTION}

$\mathrm{R} 134 \mathrm{a}$ is a synthetic refrigerant that has long been used as a working fluid in refrigerators [1]. The reason why synthetic refrigerants were chosen is understandable considering that these refrigerants generally have excellent technical properties such as very high stability, non-flammability, non-toxicity and relatively easy to obtain [2]. However, besides these good properties, R134a belongs to the HFC (hydro fluorocarbons) group [3] is a chemical compound that contributes to global climate change because this material has the potential for global warming [4,5]. Therefore, the use of R134a as the working fluid for refrigerator will not last long [6].
Scientists and researchers agree that an alternative to replacing synthetic refrigerants is to use natural refrigerants (hydrocarbons). Hydrocarbon refrigerant (HC) is a type of refrigerant that is extracted from natural gas and has a short shelf life in the atmosphere of less than one year [7]. Hydrocarbons as an alternative refrigerant have many advantages, including no need to change the existing main equipment, have chemical stability; suitability of thermodynamic physical and chemical properties with synthetic refrigerants, hydrocarbons can be used with mineral or synthetic lubricants and do not cause ozone damage and heating global because ODP owned is zero and GWP is small [8]. The hydrocarbons that are often used as refrigerants are propane (R-290), isobutene (R-600a), n-butane (R-600) [9] and propylene (R1270) [7].

$\mathrm{R}-1270$ is a hydrocarbon refrigerant with the chemical term C3H6. As shown in Table I its characteristics are suitable to replace synthetic refrigerants for refrigeration systems [10]. The strength of R-1270 is not harmful to the ozone layer (ODP-0) and has a low effect on global warming, which is $<2$. The relative capacity index (RCI) of R-1270 is better than R-22 of $27.5 \%$ [8]. However, this refrigerant has not been widely used by refrigeration machine manufacturers in their new units. This is because users are concerned about the flammability of hydrocarbon refrigerants. This characteristic is actually harmless if the refrigerant is used with the correct procedure. Hydrocarbons are flammable in the presence of two other compounds called the fire triangle: hydrocarbons, fire, and air. If one of the three factors is not available, there is no fire [11]. Based on this explanation, this study aims to obtain information on the feasibility of using R1270 as an alternative to $\mathrm{R} 134 \mathrm{a}$ on the refrigerator.

TABLE I. PROPERTIES OF REFRIGERANT [12]

\begin{tabular}{|l|l|l|l|l|l|l|}
\hline Refrigerant & composition & \multicolumn{1}{|c|}{ replaces } & $\begin{array}{c}\text { Molecular } \\
(\mathbf{w t})\end{array}$ & $\begin{array}{c}\text { Critical } \\
\text { temperature }\left({ }^{\circ} \mathbf{C}\right)\end{array}$ & $\begin{array}{c}\text { Boiling Point } \\
\left({ }^{\circ} \mathbf{C}\right)\end{array}$ & $\begin{array}{c}\text { ASHARAE } \\
\text { safety code }\end{array}$ \\
\hline R134a & Pure fluid & R12 & 102.03 & 101.1 & -26.5 & A1 \\
\hline R600a & Pure fluid & $\begin{array}{l}\text { R12, } \\
\text { R134a }\end{array}$ & 58.12 & 134.7 & -11.6 & A3 \\
\hline R600 & Pure fluid & R12, R22 & 58.12 & 152 & -0.5 & A3 \\
\hline R290 & Pure fluid & R12, R22 & 44.1 & 96.7 & -42.1 & A3 \\
\hline R1270 & Pure fluid & R22 & 42.08 & 92.4 & -47.7 & A3 \\
\hline
\end{tabular}




\section{METHODS}

Figure 1 shows a schematic diagram of the research equipment used to test the feasibility of R1270 in the refrigeration system. The test was carried out on one unit of the GEA brand refrigerator showcase with a capacity of 210 liters. The measuring instrument used consists of two manifold gauge units (Robin air) and two temperature sensor units (Elitech) each placed in the suction and discharge channels and a clamp meter (Krisbow) which is used to measure the value of electric current. Initial data collection is carried out when the evaporator temperature is $20 \mathrm{C}$ which is assumed to be in a steady state, and then each data change is recorded every six minutes for 60 minutes. The data observed included suction pressure and temperature, discharge pressure and temperature, evaporator temperature, cooling time, and electric current. This research was conducted experimentally with the default refrigerant is R134a. Replacement of the refrigerant built in by R1270 is done by using the drop in substitute method, which is replacing the refrigerant without replacing the main component.

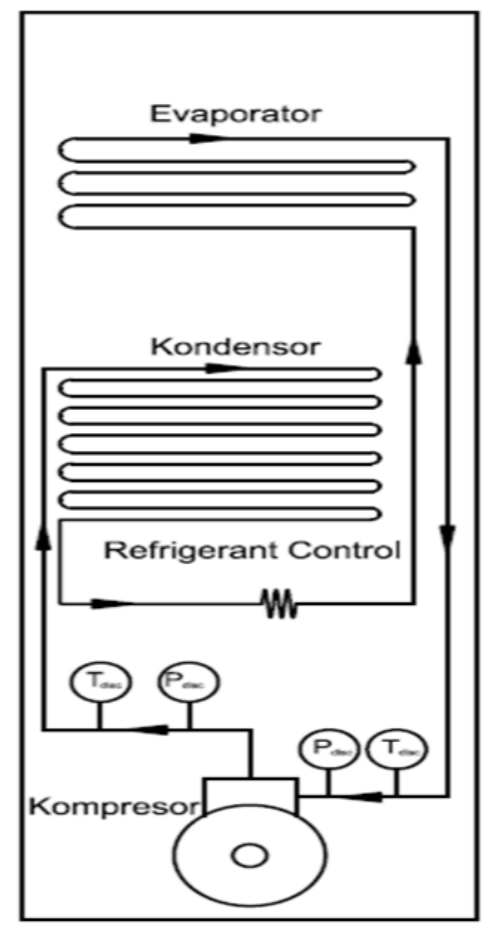

Fig. 1. Schematic diagram of the research tool.

The test procedure is carried out for two conditions, first the operation of the refrigeration cycle using R134a (base line) and secondly the operation of the refrigeration system using R1270. Data were collected four times for each condition. The stages of testing carried out in this study are first to record the ambient temperature and calibrate all measuring instruments. Furthermore, the vacuum process, check for leaks in the refrigeration system and proceed with charging R134a refrigerant weighing 100 gr according to the manufacturer's recommendations. Next, turn on the refrigeration system to start the 60-minute testing process by recording the test data at six-minute intervals. The second stage of testing uses the R1270 hydrocarbon refrigerant with the same procedure as before. The difference lies in the weight of the refrigerant charging $30 \%$ of the base line. The difference in refrigerant weight is due to the characteristics of R1270 which has a smaller molecular weight than R134a. After all the testing stages have been completed, the data is processed and analyzed to determine the feasibility of using R1270 as an alternative to R134a.

\section{RESULTS AND DISCUSSION}

The feasibility test for using R1270 as an alternative refrigerant to replace R-134a in the showcase refrigerator has been carried out. Data on changes in evaporator temperature, refrigeration effect (RE), and coefficient of performance (COP) for 60 minutes of refrigeration system operation are shown in Figure 2 to Figure 4.

\section{A. Evaporator Temperature}

The evaporator is the main component of the refrigerator which functions to absorb heat from products stored in the refrigerator. The lower the refrigerant temperature in the evaporator pipe, the more heat that can be absorbed from the stored products, results in a lower temperature. Figure 2 shows a graph of the change in evaporator temperature with respect to the operating time of the refrigerator.

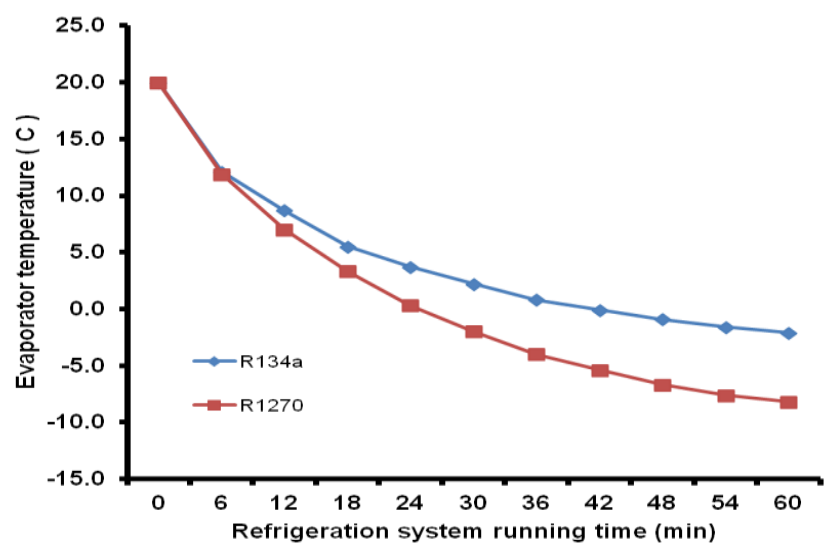

Fig. 2. Changes in evaporator temperature in testing two types of refrigerants.

At the beginning of the observation until the 6th minute, the two refrigerants reached the same evaporator temperature. Then in the next minute the achievement of the evaporator temperature for each refrigerant begins to show a difference. In the 12th minute, using the R1270 was able to reach an evaporator temperature of $7 \mathrm{C}$ and R134a of $8.7 \mathrm{C}$. Next, the increase in the operating time of the refrigerator, the achievement of the evaporator temperature by R1270 is lower than the achievement made by R134a. At the end of the test, the evaporator temperature reached by R1270 and R134a were $-8.2 \mathrm{C}$ and $-2.1 \mathrm{C}$, respectively. These results indicate that the 
use of R1270 as the working fluid for the refrigerator is able to provide a lower evaporator temperature than using R134a. So $\mathrm{R} 1270$ can be said to be feasible to replace R134a as the primary refrigerant of a refrigerator.

\section{B. Refrigeration Effect (RE)}

Figure 3 shows the refrigeration effect of using R134a and $\mathrm{R} 1270$ on the refrigerator. In general, the refrigeration effect produced by R1270 is higher than R134a. At the beginning of the test, the refrigeration effect of R134a was $124.12 \mathrm{~kJ} / \mathrm{kg}$. Then it decreased until the 24th minute of $120.45 \mathrm{~kJ} / \mathrm{kg}$. Then slightly up to $122.14 \mathrm{~kJ} / \mathrm{kg}$ in the 30th minute. Then it fell back to $120.74 \mathrm{~kJ} / \mathrm{kg}$ and was stable until the last minute. On the other hand, the use of R1270 produces a refrigeration effect of $235.25 \mathrm{~kJ} / \mathrm{kg}$ at the beginning of the test. After that, it fell slightly in the 12 th minute to $234.27 \mathrm{~kJ} / \mathrm{kg}$. After that, it gradually rose to $239.26 \mathrm{~kJ} / \mathrm{kg}$ until the end of the test. Based on these results there is an increase in the refrigeration effect of $98 \%$ on the use of R1270 as a working fluid. These results have an impact on the pressure aspect ratio to be smaller and the amount of heat that can be absorbed by the refrigerant in the evaporator is more, thereby increasing the cooling capacity [13].

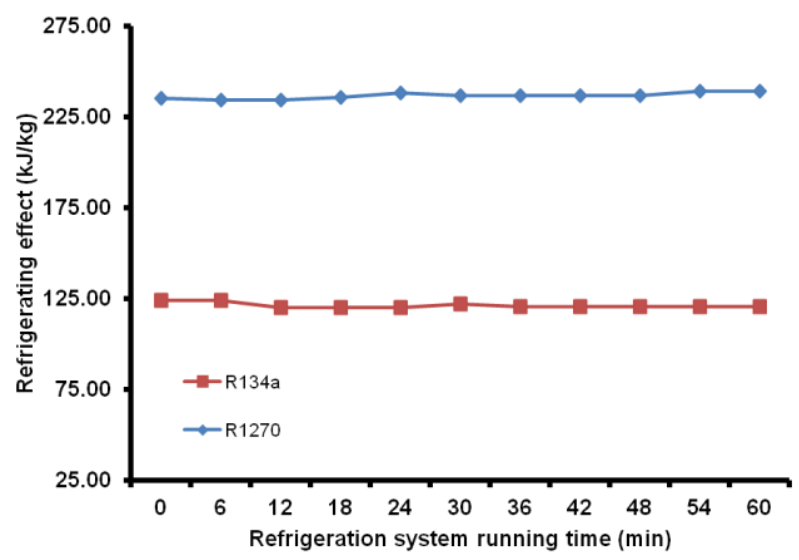

Fig. 3. The refrigeration effect of using R134a and R1270 on the refrigerator.

\section{Coefficient of Performance (COP) System}

Figure 4 shows a graph of the coefficient of performance of a refrigeration system that uses two different types of refrigerants, R134a and R1270. Globally, the COP produced by $\mathrm{R} 1270$ is greater than R134a. When using R134a, the COP obtained at the beginning of the test was 3.9 and lasted until the 6th minute. Then drop dramatically to 3.56 in the 12 th minute to the 24th minute. After that it fluctuated down to 3.43 until the end of the test.

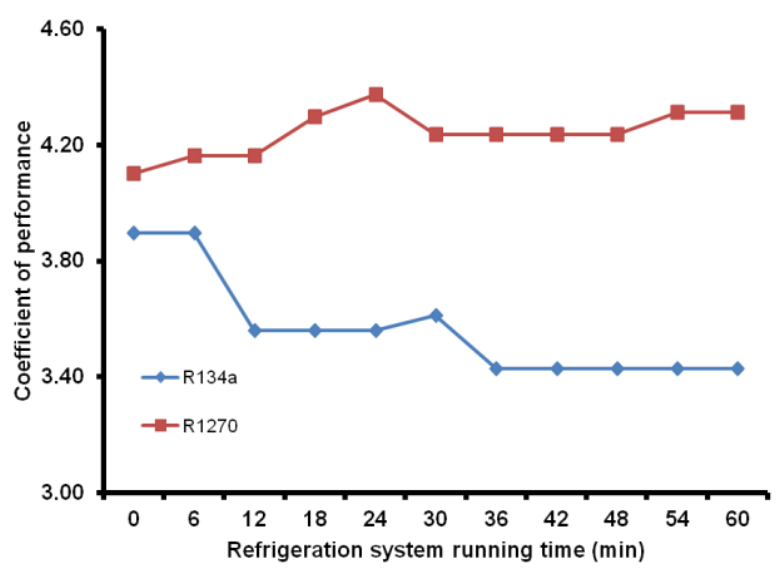

Fig. 4. The coefficient of performance of using R134a and R1270.

Different conditions with COP on R1270. At the beginning of the test, COP was recorded at 4.1. Then in the next minute the COP rose gradually until it reached its peak in the 24th minute with the acquisition of 4.37. After that the COP dropped sloping down to the end with a achievement of 4.31. Based on these results it can be said that R1270 is suitable to be used as a substitute for $\mathrm{R} 134 \mathrm{a}$ in the refrigerator directly without having to replace its constituent components [14].

\section{CONCLUSIONS}

Research on the feasibility of using R1270 as an alternative refrigerant to replace $\mathrm{R} 134 \mathrm{a}$ in refrigerators has been carried out. The results showed that COP increased $26 \%$ and the evaporator temperature was $6 \mathrm{C}$ lower after replacing R134a by $\mathrm{R} 1270$. These results have implications for the feasibility of $\mathrm{R} 1270$ to replace $\mathrm{R} 134 \mathrm{a}$ as the refrigerator working fluid.

\section{ACKNOWLEDGMENT}

This research was supported by funding from Universitas Pendidikan Indonesia (UPI) fiscal year 2020, "Skim Penelitian Penguatan Kompetensi”.

\section{REFERENCES}

[1] M.A. Alsaad and M.A. Hammad, "The application of propane/butane mixture for domestic refrigerators," Appl. Therm. Eng., vol. 18, no. 910, pp. 911-918, 1998.

[2] R.L. Powell, "CFC phase-out: Have we met the challenge?," J. Fluor. Chem., vol. 114, no. 2, pp. 237-250, 2002.

[3] K. Harby, "Hydrocarbons and their mixtures as alternatives to environmental unfriendly halogenated refrigerants: An updated overview,” Renew. Sustain. Energy Rev., vol. 73, no. December 2015, pp. 1247-1264, 2017

[4] B.O. Bolaji, "Experimental study of R152a and R32 to replace R134a in a domestic refrigerator," Energy, vol. 35, no. 9, pp. 3793-3798, 2010

[5] A. Baskaran and P. Koshy Mathews, "A Performance Comparison of Vapour Compression Refrigeration System Using Eco Friendly 
Refrigerants of Low Global Warming Potential,’ Int. J. Sci. Res. Publ., vol. 2, no. 1, pp. 2250-3153, 2012.

[6] S. Wongwises, A. Kamboon, and B. Orachon, "Experimental investigation of hydrocarbon mixtures to replace HFC-134a in an automotive air conditioning system," Energy Convers. Manag., vol. 47, no. 11-12, pp. 1644-1659, 2006.

[7] N. Kamal, "Design of Domestic refrigerator using Propylene ( R1270 ) as refrigerant," vol. 02, no. 04, pp. 14-18, 2017.

[8] R.N. Richardson and J.S. Butterworth, "The performance of propane/isobutane mixtures in a vapour-compression refrigeration system,” Int. J. Refrig., vol. 18, no. 1, pp. 58-62, 1995.

[9] M. Mohanraj, S. Jayaraj, and C. Muraleedharan, "Environment friendly alternatives to halogenated refrigerants-A review," International Journal of Greenhouse Gas Control, vol. 3, no. 1. pp. 108-119, 2009.
[10] K.J. Park, T. Seo, and D. Jung, "Performance of alternative refrigerants for residential air-conditioning applications,” Appl. Energy, vol. 84, no. 10, pp. 985-991, 2007.

[11] W. Zhang, Z. Yang, J. Li, C.X. Ren, and D. Lv, "Study of the explosion characteristics and combustion products of air conditioner using flammable refrigerants," J. Fire Sci., vol. 33, no. 5, pp. 405-424, 2015.

[12] J.M. Calm and G.C. Hourahan, "Refrigerant data summary," Engineered Systems, vol. 18, no. 11.2001

[13] E.T. Berman, M. Komaro, M. Miftakhudin, M. Mutaufiq, and A. Suherman, "Enhancing performance of wall mounted split air conditioner using capillary tube in a tube heat exchanger," IOP Conf. Ser. Mater. Sci. Eng., vol. 830, no. 4, 2020.

[14] M. Mutaufiq, H. Sulistyo, E.T. Berman, and A. Wiyono, "Investigasi Eksperimental Retrofit Refrigeran Pada Alat Praktik Refrigerator dengan Refrigeran Produk Domestik yang Ramah Lingkungan,” vol. V, no. 2 , pp. 51-57, 2019. 